\title{
CORRIGENDUM
}

\section{Mutation spectrum of Joubert syndrome and related disorders among Arabs}

Salma Ben-Salem, Aisha M Al-Shamsi, Joseph G Gleeson, Bassam R Ali and Lihadh Al-Gazali

Human Genome Variation (2015) 2, 15001; doi:10.1038/hgv.2015.1; published online 26 March 2015

Correction to: Human Genome Variation (2014) 1, 14020; doi:10.1038/hgv.2014.20; published online 6 November 2014

After online publication of this review, the authors noticed couple of errors in Table 2 in the descriptions of mutations. There was also a formatting error. Corrected table with corrections highlighted appears below.

The authors apologize for any inconvenience caused.

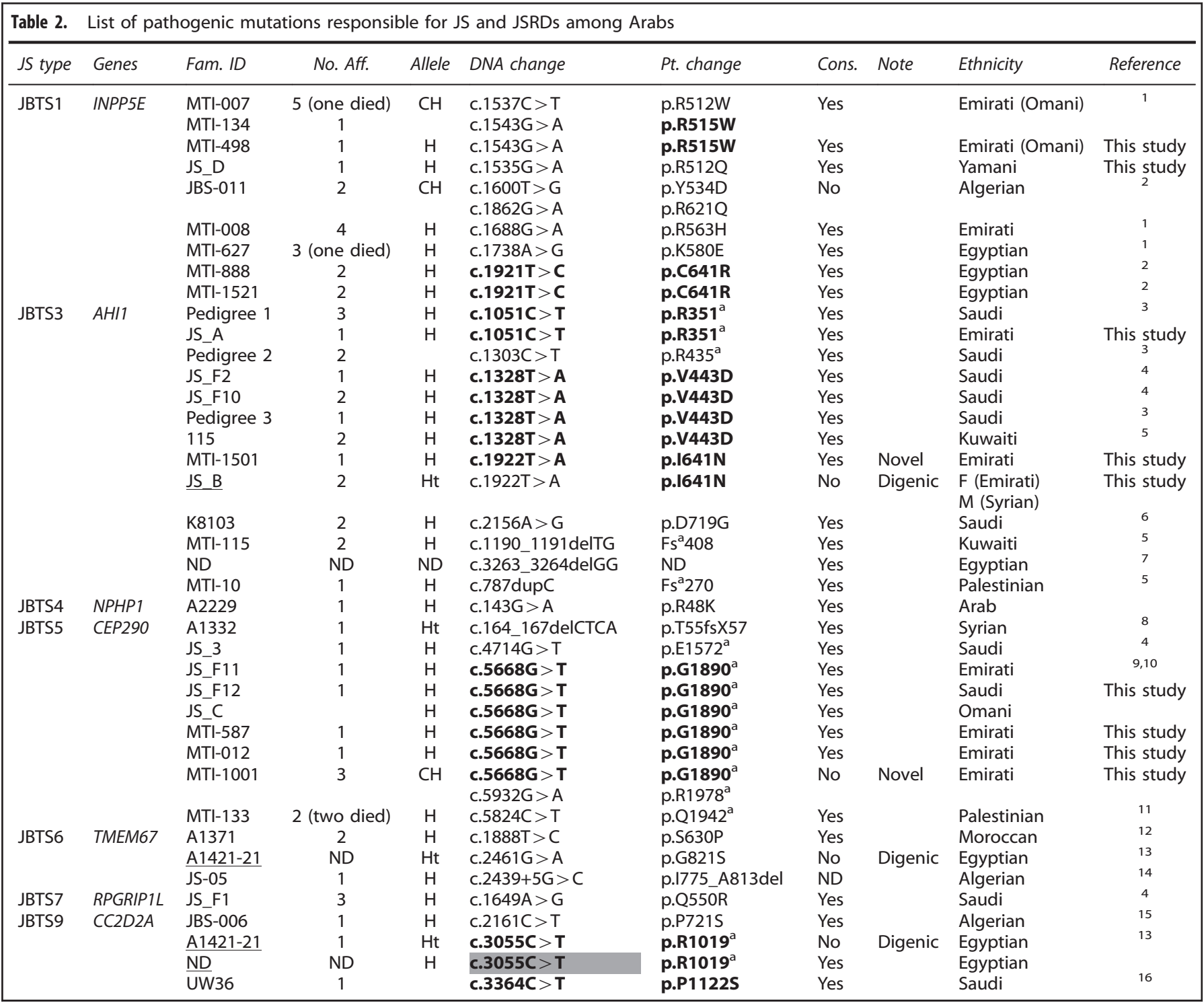




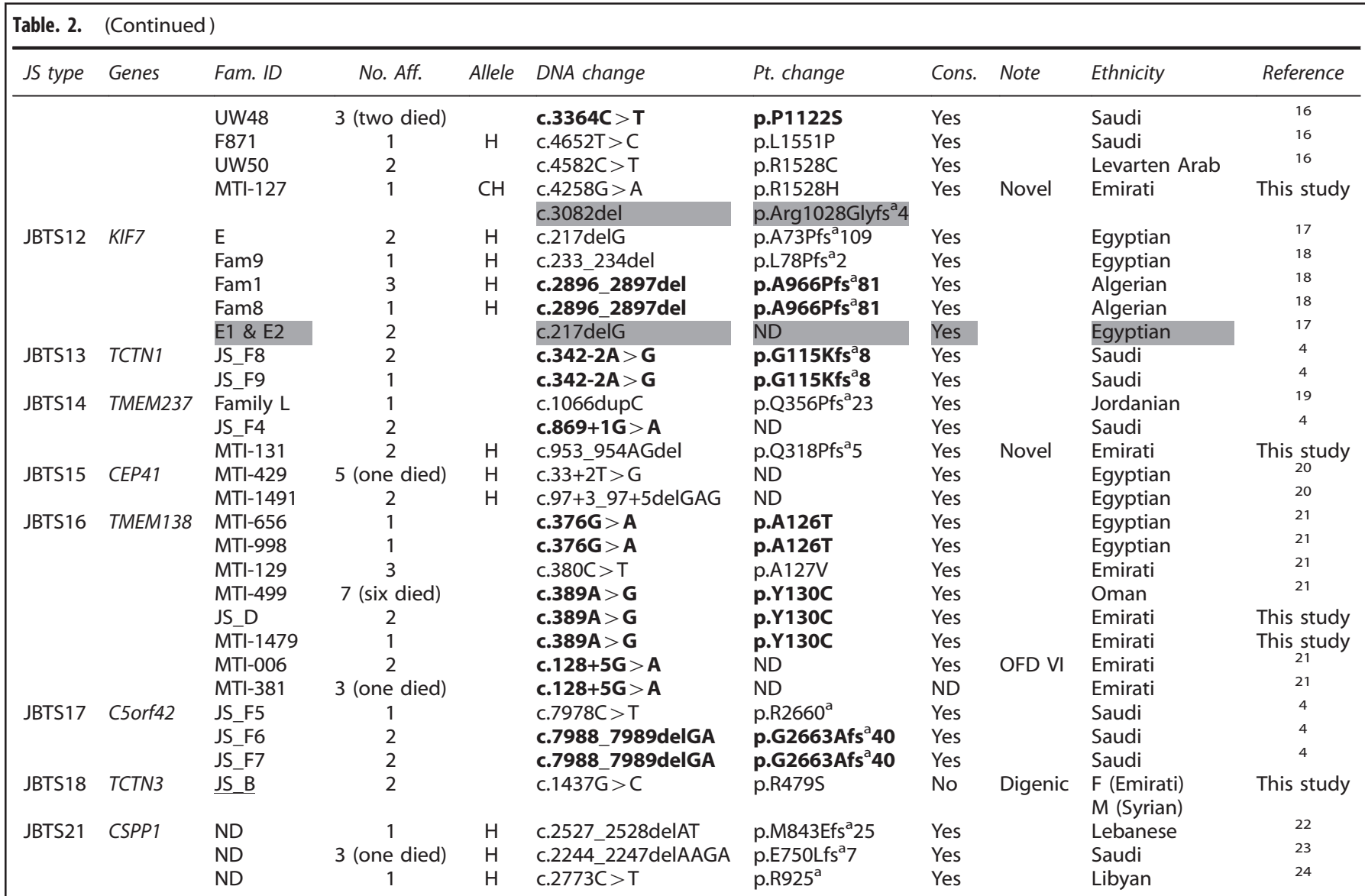

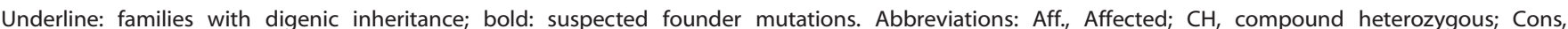
consanguinity; F, Female; Fam, family; fs, frameshift; $\mathrm{H}$, Homozygous; $\mathrm{Ht}$, Heterozygous; JBTS, JS, Joubert syndrome; JSRD, Joubert syndrome-related diorders;

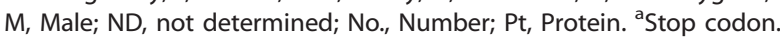

